\title{
Sex and Gender are Not the Same: Why Identity Is Important for People Living with HIV and Chronic Pain
}

This article was published in the following Dove Press journal: Journal of Pain Research

\author{
Larissa J Strath (D) \\ Robert E Sorge (D) \\ Michael A Owens' \\ Cesar E Gonzalez' \\ Jennifer I Okunbor' \\ Dyan M White' \\ Jessica S Merlin² \\ Burel R Goodin (D) \\ 'University of Alabama at Birmingham, \\ Department of Psychology, Birmingham, \\ AL, USA; ${ }^{2}$ University of Pittsburgh, \\ Department of Medicine, Divisions of \\ General Internal Medicine and Infectious \\ Diseases, Pittsburgh, PA, USA
}

Correspondence: Robert E Sorge

Tel + | 205-934-8563

Fax $+\mid 205-975-6110$

Email rsorge@uab.edu
Background: Sex differences in pain sensitivity have been well documented, such that women often report greater sensitivity than men. However, clinical reports highlighting sex differences often equate gender and sex. This is a particularly critical oversight for those whose gender identity is different than their genetic sex.

Methods: This preliminary study sets to analyze differences in pain responses between cisgender and transgender individuals living with HIV and chronic pain. A total of 51 African-American participants (24 cisgender men, 20 cisgender women, 7 transgender women) with similar socioeconomic status were recruited. Genetic sex, gender identity, depression and anxiety, pain severity, pain interference and pain-related stigma were recorded. Participants also completed a quantitative sensory testing battery to assess pain in response to noxious heat and mechanical stimuli.

Results: Transgender women and cisgender women demonstrated a greater magnitude of temporal summation for heat pain stimuli or mechanical stimuli compared to cisgender men. Specifically, transgender women reported greater mechanical summation than either cisgender women or cisgender men. Transgender women and cisgender women similarly reported greater chronic pain severity compared to cisgender men.

Conclusion: These data support the notion that gender identity may play a more significant role in pain sensation than genetic sex. These results further maintain that not only gender identity and genetic sex are distinct variables but that treatment should be based on identity as opposed to genetic sex.

Keywords: transgender, gender identity, sex differences, pain, quantitative sensory testing

\section{Introduction}

Chronic pain is a major health concern with ever-increasing costs, ${ }^{1,2}$ but the burden is not equal. Sex differences exist in the prevalence of chronic pain conditions and pain sensitivity ${ }^{3-5}$ with females reporting more pain and greater sensitivity to stimuli. ${ }^{6,7}$ $\mathrm{We}^{8,9}$ and others ${ }^{10,12}$ have demonstrated sex differences in immune cell mediation of chronic pain in rodents to complement the reported sex differences in immune cell populations and responses in humans. ${ }^{13-16}$ As such, biological sex remains a significant factor related to pain experience.

The terms "sex" and "gender" have been used interchangeably in reports using human subjects, but they are not the same. Genetic/natal sex is defined by biological differences between males and females due to genetics and hormones. Gender identity refers to the social and psychologically constructed sense of oneself as a man or 
woman. ${ }^{17}$ Research has shown that gender role expectations of pain explained more variability in pain sensitivity than genetic sex and was predictive of responses to nociceptive stimuli. ${ }^{18}$ These results suggest sex differences in rodents, may be less directly translatable to human subjects with accompanying genders.

Transgender individuals, whose gender identities are not traditionally associated with their genetic sex, ${ }^{19}$ have been disregarded and understudied in healthcare settings. ${ }^{20}$ Whereas studies have examined sociodemographics, ${ }^{21}$ healthcare access, ${ }^{22}$ social support ${ }^{23}$ and other health-related behaviors, ${ }^{24}$ little attention is given to specific health outcomes. This preliminary report describes the impact of gender identity on pain sensitivity in a sample of transgender women (TW) in comparison to cisgender men (CM) and women (CW). The first exploration of its kind, this study highlights the critical need for research in this area.

\section{Methods}

Participants for this study were a part of an on-going study examining the effects of HIV on chronic pain. As such, a complete methodology can be found elsewhere. ${ }^{25}$ All participants provided written informed consent and study procedures were approved by the University of Alabama at Birmingham Institutional Review Board and conducted in compliance with the Declaration of Helsinki.

\section{Medical Screening}

Medical record reviews were completed to determine whether participants were prescribed antidepressants or opioids. For TW, estradiol prescription and dose were noted. Those who met study inclusion criteria were deemed eligible for ongoing participation. Blood was collected from each participant for the quantification of CD4 helper T-cell count (cells/microliter) and viral load (viruses/microliter) to confirm immune health and analyze HIV-related effects. Participants with 50 viruses/microliter of blood or greater were considered to have "detectable" viral loads.

\section{Participants}

A total of 51 African-American adults (age $\geq 18$ years) were selected for this preliminary report. Chronic pain was defined as bodily pain that had persisted for at least three consecutive months and that was present on at least half the days in the past 6 months ${ }^{26}$ and confirmed by medical records. No one chronic pain condition was targeted or excluded. Of the 51 participants that completed the study, 24 were CM, 20 were CW and 7 were TW. Following identification of our TW population, we identified comparable $\mathrm{CM}$ and $\mathrm{CW}$ participants in the study population based on race, SES and age variables known to contribute to pain sensitivity. ${ }^{27-30}$ The post hoc examination reported herein and the primary focus of the data collection effort resulted in unequal groups and no representation of transgender men, factors that future studies will seek to remedy.

\section{Quantitative Sensory Testing (QST)}

Our QST methodology has been described elsewhere. ${ }^{25}$ In short, heat pain threshold (HPTh), heat pain tolerance (HPTo), and temporal summation (TS) of heat pain were assessed prior to TS of mechanical pain. Following TS procedure, conditioned pain modulation (CPM) was assessed.

\section{Psychosocial Measures}

Participants completed self-report questionnaires that included: the HIV Stigma Mechanism Measure, ${ }^{31}$ the Center for Epidemiological Studies-Depression Scale (CES-D), ${ }^{32}$ the State-Trait Anxiety Index (STAI), ${ }^{33}$ the Everyday Discrimination Scale, ${ }^{34}$ the 36-Item Short Form Health Survey (SF-36), ${ }^{35}$ the Pain Sensitivity Questionnaire (PSQ), ${ }^{36}$ the Pain Catastrophizing Scale (PCS), ${ }^{37}$ Internalized Stigma of Chronic Pain Scale, ${ }^{38}$ and the Brief Pain Inventory (BPI)-Short Form. ${ }^{39,40}$

\section{Statistical Analyses}

Differences in participant characteristics were examined using analysis of variance (ANOVA). Analyses included analgesics and antidepressants as covariates. For continuously measured variables, a repeated-measures ANOVA was used to analyze group differences. Differences in pain sensitivity were analyzed by ANOVA with post hoc analyses for pairwise comparisons across the three study groups. Finally, a correlation analysis was completed to assess the association of psychosocial variables with mechanical and heat pain sensitivity. There were no missing data for any of the study variables. All analyses were carried out using SPSS, version 24.

\section{Results}

\section{Demographics}

All participants (aged $46 \pm 1$ years of age) were HIV-positive and living below the poverty line according to government standards. Sixteen had a detectable viral load $(\mathrm{CM}=11$; $\mathrm{CW}=4 ; \mathrm{TW}=1)$. The average number of CD4+ cells was 
$662(\mathrm{CM}=541 ; \mathrm{CW}=798 ; \mathrm{TW}=693)$. Thirty-four had current prescriptions for antidepressants and 35 had current prescriptions for analgesics. Only 5 of 7 TW participants had prescriptions for estradiol in varying doses in their medical records. Estradiol prescription did not predict pain scores, nor did estradiol dose in any test. Neither antidepressants nor analgesics had any effects on acute pain sensitivity measures differentially between groups.

\section{Heat Pain Sensitivity}

There were no significant differences between gender groups for HPTh or HPTo (Figure 1A and B). There was a significant main effect of antidepressant prescription for HPTh (F $(1,51)=4.410, \mathrm{p}=0.041 ; \eta_{\mathrm{p}}{ }^{2}=0.086,1-\beta=0.539$ and HPTo $\left(\mathrm{F}(1,51)=4.131, \mathrm{p}=0.048 ; \eta_{\mathrm{p}}{ }^{2}=0.081,1-\beta=0.512\right)$, but no interaction with gender groups. TS of heat pain was determined by the change in the pain intensity rating elicited by the first heat pulse compared to the rating elicited by the fifth heat pulse for the $46^{\circ} \mathrm{C}$ stimulus. Data representing TS of heat pain and ratings over time are presented in Figure 2A and $\mathrm{B}$. Results of a repeated-measures ANOVA revealed that the magnitude of TS (ie, slope) did not differ according to gender identity. There was a significant main effect of analgesic prescription on $\mathrm{TS}(\mathrm{F}(1,51)=5.239, \mathrm{p}=0.027$; $\left.\eta_{\mathrm{p}}{ }^{2}=0.0 .005,1-\beta=0.068\right)$, but no interaction with gender groups. Absolute pain intensity ratings in response to the repeated $46^{\circ} \mathrm{C}$ heat stimuli significantly differed according to gender identity $\left(\mathrm{F}(1,51)=7.347, \mathrm{p}=0.002 ; \eta_{\mathrm{p}}{ }^{2}=0.234,1-\right.$ $\beta=0.924)$ ). Specifically, TW $(p=0.014)$ and $C W(p=0.019)$ rated the intensity of pain elicited by each of the five heat pulses as significantly greater in comparison to CM. Pain intensity ratings to the $46^{\circ} \mathrm{C}$ heat pulses did not significantly differ between TW and CW.

\section{Mechanical Pain Sensitivity}

TS of mechanical pain was determined by calculating the change in the pain intensity rating elicited by the first contact with the nylon monofilament compared to the rating elicited following the series of 10 contacts, presented in Figure $2 \mathrm{C}$ and D. Repeated-measures ANOVA revealed a significant effect of gender on TS of mechanical pain $(\mathrm{F}(1,51)=4.647, \mathrm{p}=0.015$; $\eta_{\mathrm{p}}{ }^{2}=0.168,1-\beta=0.756$ ). Specifically, the magnitude (ie slope) of TS for mechanical pain demonstrated by TW was significantly greater than the TS demonstrated by CM $(\mathrm{p}=0.013)$, but not $\mathrm{CW}(\mathrm{p}=0.078)$, though there was a trend. There were no significant effects of antidepressants or analgesics on mechanical sensitivity.

\section{Conditioned Pain Modulation}

For CPM, baseline pressure pain thresholds (PPTs) were compared to conditioned PPTs (ie, PPTs assessed during concurrent cold pressor application). There were no significant effects of gender on baseline PPTs or conditioned PPTs (Figure 1C). Further, there was no significant effect of gender on CPM.

\section{Psychosocial Variables}

There were no significant effects of gender identity on any of the psychosocial variables (data not shown) or evidence
A

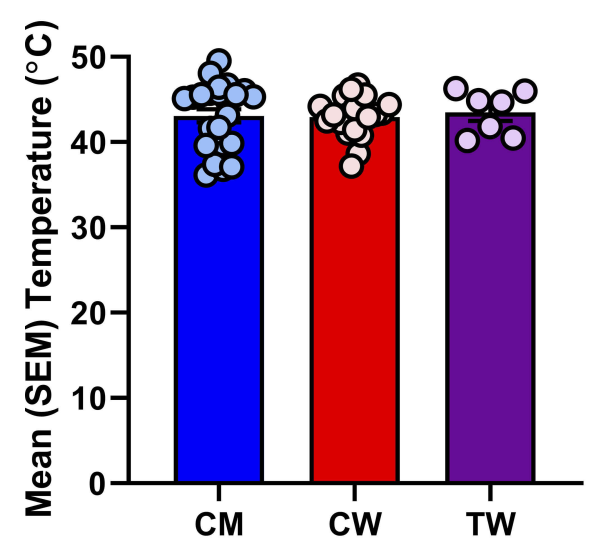

Gender Identity
B

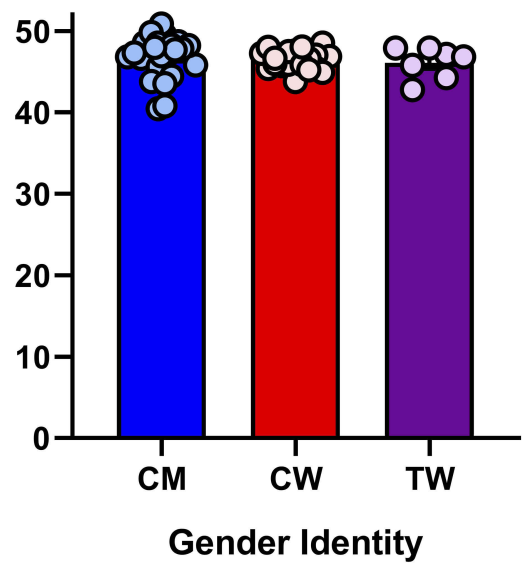

C

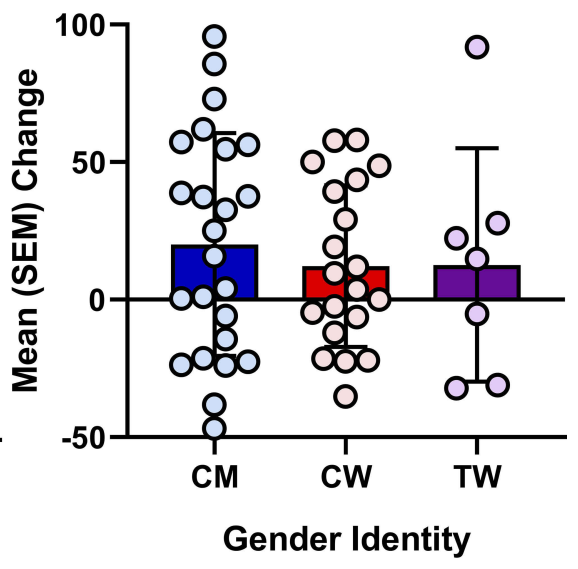

Figure I (A) Mean (SEM) temperature threshold $\left({ }^{\circ} \mathrm{C}\right)$ when pain was detected. (B) Mean $(\mathrm{SEM})$ temperature tolerance $\left({ }^{\circ} \mathrm{C}\right) .(\mathbf{C})$ Mean $(\mathrm{SEM})$ change in pressure pain threshold (conditioned pain modulation) as a result of simultaneous exposure to the cold pressor and to pressure pain stimuli. $\mathrm{CM}=$ cisgender men (blue), $\mathrm{CW}=$ cisgender women (red), TW = transgender women (purple), individual circles represent participant values contributing to the overall means for each group. 
A

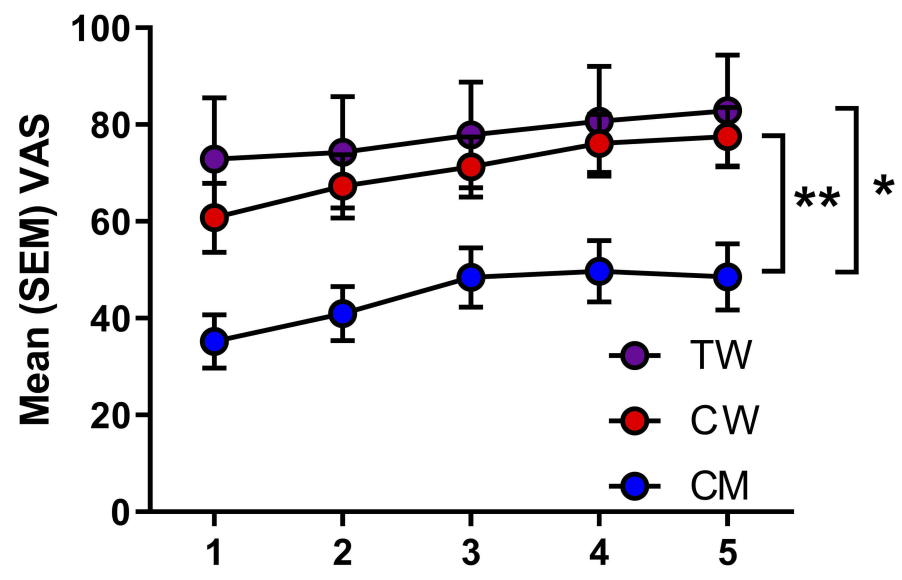

C

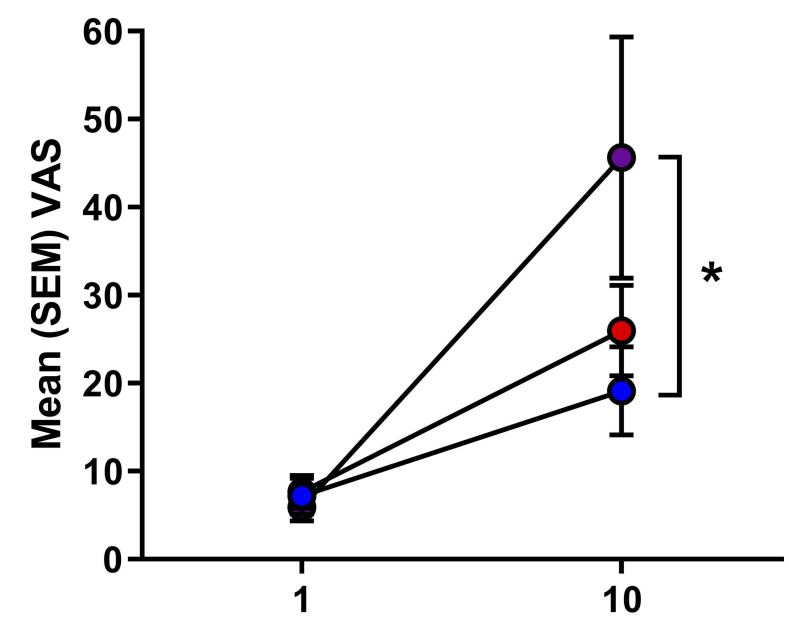

Presentation Number
B

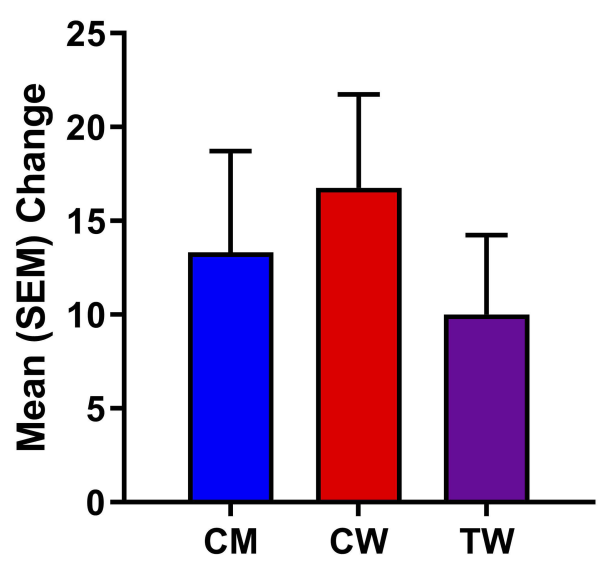

Gender Identity

D

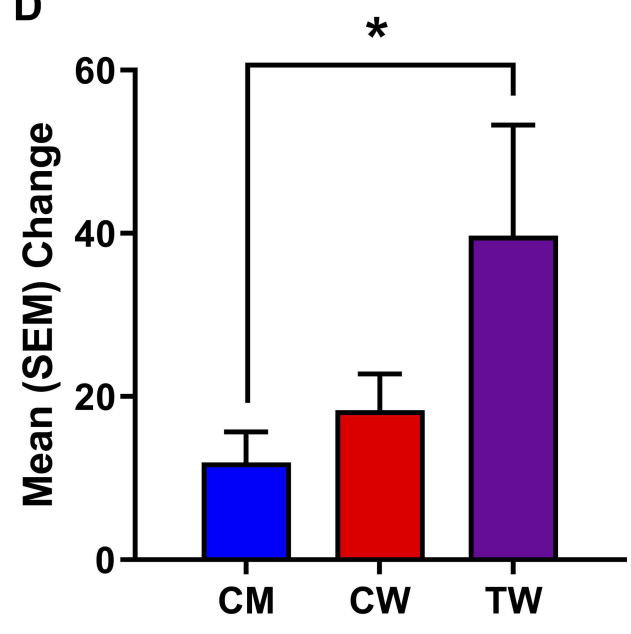

Gender Identity

Figure 2 (A) Mean (SEM) visual analogue scale (VAS) pain ratings for the individual heat pulses. (B) Mean (SEM) change in VAS pain rating from pulse I to pulse 5. (C) Mean (SEM) VAS rating for the temporal summation of mechanical pain at I presentation and 10 presentations of $300 \mathrm{~g}$ monofilament. (D) Mean (SEM) change in VAS pain rating from I presentation to 10 presentations. $C M=$ cisgender men (blue), $C W=$ cisgender women (red), $\mathrm{TW}=$ transgender women (purple). ${ }^{*} \mathrm{p}<0.05,{ }^{*} \mathrm{p}<0.0 \mathrm{I}$.

of significant correlations among the QST responses and psychosocial variables.

\section{Discussion}

To our knowledge, this is the first report to explore whether transgender individuals respond to pain more similarly to their genetic sex or their gender identity. Our preliminary findings suggest that TW respond to noxious mechanical and heat stimuli more similarly to $\mathrm{CW}$ and not $\mathrm{CM}$, though not always statistically significant. In the case of TS of heat and mechanical pain, both TW and CW showed greater pain sensitivity compared to CM, but did not differ from one another. These findings could not be accounted for by any psychosocial variables, despite their relevance elsewhere. We assert that selection of comparator groups reduced the impact of these variables. In our preliminary study, gender identity was the major contributing factor to the summation of noxious stimuli, not genetic sex.

In preclinical studies, genetic sex is a significant biological variable. Our early work demonstrated sex differences in the role of immune cells in the mediation of chronic pain. ${ }^{8,9}$ Others have replicated our work across species $^{11}$ and various chronic pain models ${ }^{10,12}$. In each case, the utilization of specific immune cells was found to hormone-dependent. ${ }^{9,11,41}$ In fact, there is evidence in humans of similar differences in immune cell responses, ${ }^{14}$ 
populations $^{13,15,16}$ and hormone-dependence ${ }^{42}$ that encourages the translatability of the preclinical work. However, emerging evidence suggests that psychosocial factors can modulate pain in rodents in ways that mirror human interactions. ${ }^{4,44}$

Social and cultural factors can alter pain experience. Women with chronic pain report greater hostility and dismissal $^{45}$ and are more likely to have their pain attributed to psychological issues. ${ }^{46}$ These disparities appear to be reinforced through gender stereotypes that attribute distinct pain resilience patterns for men and women. The Gender Role Expectations of Pain Questionnaire (GREP) was developed to examine the impact of these beliefs. ${ }^{18}$ Researchers using the GREP have demonstrated that gender identity predicted more of the variability in responses than genetic sex. ${ }^{47}$ These data support the notion that beliefs about pain sensitivity may play a greater role than other biological variables, in alignment with the striking similarity in summation responses between $\mathrm{CW}$ and TW in our study. However, there are biologically based reasons for expecting that TW and CW would show similar responses.

Central sensitization is a phenomenon whereby nociceptor stimulation can increase the excitability of neurons in central pain pathways manifesting as pain hypersensitivity ${ }^{48-50}$ and may underlie chronic pain. In support of clinical epidemiological data, there is evidence to suggest that central sensitization and resulting secondary hyperalgesia are indeed greater in women, ${ }^{51}$ possibly accounting for the greater prevalence of chronic pain in women. To that end, temporal summation may be predictive of the development of chronic pain ${ }^{52}$ and we have reported putative sex differences in temporal summation of heat, ${ }^{53}$ but we are the first to expand these investigations to TW. Additionally, in pain-relevant brain regions such as the thalamus, hypothalamus, putamen, INAH3 subnucleus and the bed nucleus of the stria terminalis, there are documented differences in neuron number, connectivity and cortical thickness that are dependent on gender identity, as opposed to genetic sex. ${ }^{54-59}$ There is debate as to whether these similarities are innate ${ }^{60}$ or due to social factors, ${ }^{61,62}$ but gender identity appears to be a critical component. These data suggest that TW may be at increased risk for central sensitization, hypersensitivity and subsequent chronic pain. Therefore, we assert that gender identity be recognized as a critical factor in treatment recommendations and future studies.

Our study had a number of limitations due to the preliminary nature of the work. First, the sample size for the TW group was small, based on the conditions surrounding the collection of the data and the focus of the parent project. Second, the lack of transgender men in the study is an aspect that future studies should address. Third, to provide comparator groups to the TW in the study, we selected participants that were similar in race, SES and health status. This choice increased internal validity but may result in data that is not generalizable to the population as a whole. Fourth, as mentioned, we did not test hormone status and there is ample data to suggest that hormones affect the mediation of chronic pain. ${ }^{8,9}$ We feel that the limitations of our study do not reduce the potential importance of our work and believe that future large-scale studies can overcome these obstacles to provide a clearer understanding of the role that gender identity plays on pain sensitivity in humans.

The transgender community is a vulnerable population dealing with stigmas that impact the quality of life. ${ }^{21,63}$ Despite the evidence of sex differences in pain that are dependent on hormone status and genetic sex, there are a host of reasons for caution when applying such findings. Our study demonstrated that TW and CW show very similar temporal summation of thermal stimuli and that TW may have an even greater summation of mechanical stimuli than $\mathrm{CW}$. This latter finding argues that TW may be at greater risk for chronic pain than $\mathrm{CW}$, supporting the need for further study and assistance. In our hands, gender identity appears to have a significant impact on pain sensitivity, supporting the recognition of gender identity over genetic sex.

\section{Acknowledgments}

The authors would like to acknowledge the efforts of the staff at the UAB CCTS Clinical Research Unit for their assistance with data collection, sample preparation and blood analysis, as well as Tammie Quinn for aiding with the conceptualization of the manuscript.

\section{Author Contributions}

All authors made substantial contributions to conception and design, acquisition of data, or analysis and interpretation of data; took part in drafting the article or revising it critically for important intellectual content; gave final approval of the version to be published; and agree to be accountable for all aspects of the work.

\section{Funding}

This research was supported by the Creative and Novel Ideas in HIV Research Program (B.R.G.) through a supplement to the University of Alabama at Birmingham 
Center for AIDS Research funding (P30AI027767). This funding was made possible by collaborative efforts of the Office of AIDS Research, the National Institute of Allergy and Infectious Diseases, and the International AIDS Society. Additional financial support for this work was made available by the National Heart, Lung and Blood Institute under award number R01HL147603 (B.R.G.).

\section{Disclosure}

The authors declare no personal or financial conflicts of interest in this work.

\section{References}

1. Green CR, Anderson KO, Baker TA, et al. The unequal burden of pain: confronting racial and ethnic disparities in pain. Pain Med. 2003;4(3):277-294. doi:10.1046/j.1526-4637.2003.03034.x

2. Green CR. Being present: the role of narrative medicine in reducing the unequal burden of pain. Pain. 2011;152(5):965-966. doi:10.1016/ j.pain.2011.01.041

3. Berkley KJ. Sex differences in pain. Behav Brain Sci. 1997;20 (3):371-380; discussion 435-513. doi:10.1017/S0140525X97221485

4. Fillingim RB, CD K, Ribeiro-Dasilva MC, Rahim-Williams B, JL R 3rd. Sex, gender, and pain: a review of recent clinical and experimental findings. J Pain. 2009;10(5):447-485. doi:10.1016/j.jpain.2008.12.001

5. Fillingim RB. Sex, gender, and pain: women and men really are different. Curr Rev Pain. 2000;4(1):24-30. doi:10.1007/s11916-0000006-6

6. Riley JL 3rd, Gilbert GH, Heft MW. Orofacial pain symptom prevalence: selective sex differences in the elderly? Pain. 1998;76(12):97-104. doi:10.1016/S0304-3959(98)00030-X

7. Mogil JS. Sex differences in pain and pain inhibition: multiple explanations of a controversial phenomenon. Nat Rev Neurosci. 2012;13(12):859-866. doi:10.1038/nrn3360

8. Sorge RE, LaCroix-Fralish ML, Tuttle AH, et al. Spinal cord Tolllike receptor 4 mediates inflammatory and neuropathic hypersensitivity in male but not female mice. J Neurosci. 2011;31(43):1545015454. doi:10.1523/JNEUROSCI.3859-11.2011

9. Sorge RE, Mapplebeck JC, Rosen S, et al. Different immune cells mediate mechanical pain hypersensitivity in male and female mice. Nat Neurosci. 2015;18:1081-1083.

10. Chen G, Luo X, Qadri MY, Berta T, Ji RR. Sex-dependent glial signaling in pathological pain: distinct roles of spinal microglia and astrocytes. Neurosci Bull. 2017.

11. Mapplebeck JCS, Dalgarno R, Tu Y, et al. Microglial P2X4R-evoked pain hypersensitivity is sexually dimorphic in rats. Pain. 2018;159 (9):1752-1763. doi:10.1097/j.pain.0000000000001265

12. Taves S, Berta T, Liu DL, et al. Spinal inhibition of p38 MAP kinase reduces inflammatory and neuropathic pain in male but not female mice: sex-dependent microglial signaling in the spinal cord. Brain Behav Immun. 2015.

13. Abdullah M, Chai PS, Chong MY, et al. Gender effect on in vitro lymphocyte subset levels of healthy individuals. Cell Immunol. 2012;272(2):214-219. doi:10.1016/j.cellimm.2011.10.009

14. Wegner A, Elsenbruch S, Rebernik L, et al. Inflammation-induced pain sensitization in men and women: does sex matter in experimental endotoxemia? Pain. 2015;156(10):1954-1964. doi:10.1097/j. pain.0000000000000256

15. Amadori A, Zamarchi R, De Silvestro G, et al. Genetic control of the CD4/CD8 T-cell ratio in humans. Nat Med. 1995;1(12):1279-1283. doi:10.1038/nm1295-1279
16. Sankaran-Walters S, Macal M, Grishina I, et al. Sex differences matter in the gut: effect on mucosal immune activation and inflammation. Biol Sex Differ. 2013;4(1):10. doi:10.1186/2042-6410-4-10

17. Torgrimson BN, Minson CT. Sex and gender: what is the difference? J Appl Physiol. 2005;99(3):785-787. doi:10.1152/japplphysiol.003 76.2005

18. Robinson ME, Riley JL, Myers CD, et al. Gender role expectations of pain: relationship to sex differences in pain. J Pain. 2001;2(5):251257. doi:10.1054/jpai.2001.24551

19. Mayer KH, Bradford JB, Makadon HJ, Stall R, Goldhammer H, Landers S. Sexual and gender minority health: what we know and what needs to be done. Am J Public Health. 2008;98(6):989-995. doi:10.2105/AJPH.2007.127811

20. Fredriksen-Goldsen KI, Cook-Daniels L, Kim H-J, et al. Physical and mental health of transgender older adults: an at-risk and underserved population. Gerontologist. 2013;54(3):488-500. doi:10.1093/geront/ gnt021

21. Motmans J, Meier P, Ponnet K, Female TG. Male transgender quality of life: socioeconomic and medical differences. J Sex Med. 2012;9 (3):743-750. doi:10.1111/j.1743-6109.2011.02569.x

22. Kenagy GP. Transgender health: findings from two needs assessment studies in Philadelphia. Health Soc Work. 2005;30(1):19-26. doi:10.1093/hsw/30.1.19

23. Budge SL, Adelson JL, Howard KAS. Anxiety and depression in transgender individuals: the roles of transition status, loss, social support, and coping. J Consult Clin Psychol. 2013;81(3):545-557. doi:10.1037/a0031774

24. Poteat T, German D, Kerrigan D. Managing uncertainty: a grounded theory of stigma in transgender health care encounters. Soc Sci Med. 2013;84:22-29. doi:10.1016/j.socscimed.2013.02.019

25. Owens MA, Parker R, Rainey RL, et al. Enhanced facilitation and diminished inhibition characterizes the pronociceptive endogenous pain modulatory balance of persons living with HIV and chronic pain. J Neurovirol. 2019;25(1):57-71. doi:10.1007/s13365-0180686-5

26. Treede RD, Rief W, Barke A, et al. A classification of chronic pain for ICD-11. Pain. 2015;156(6):1003-1007. doi:10.1097/j.pain.00000 00000000160

27. Cruz-Almeida Y, Sibille KT, Goodin BR, et al. Racial and ethnic differences in older adults with knee osteoarthritis. Arthritis Rheumatol. 2014;66(7):1800-1810. doi:10.1002/art.38620

28. Goodin BR, Pham QT, Glover TL, et al. Perceived racial discrimination, but not mistrust of medical researchers, predicts the heat pain tolerance of African Americans with symptomatic knee osteoarthritis. Health Psychol. 2013;32(11):1117-1126. doi:10.10 37/a0031592

29. Herbert MS, Goodin BR, Bulls HW, et al. Ethnicity, cortisol, and experimental pain responses among persons with symptomatic knee osteoarthritis. Clin J Pain. 2017;33(9):820-826. doi:10.1097/ AJP.0000000000000462

30. Thompson KA, Terry EL, Sibille KT, et al. At the intersection of ethnicity/race and poverty: knee pain and physical function. J Racial Ethn Health Disparities. 2019;6:1131-1143.

31. Earnshaw VA, Chaudoir SR. From conceptualizing to measuring HIV stigma: a review of HIV stigma mechanism measures. AIDS Behav. 2009;13(6):1160-1177. doi:10.1007/s10461-009-9593-3

32. Radloff LS. The CES-D scale: a self report depression scale for research in the general population. Appl Psychol Meas. 1977;1:385401.

33. Speilberger CD, Gorsuch RL, Lushene R, et al. Manual for the StateTrait Anxiety Inventory. Palo Alto, CA: Consulting Psychologists Press; 1983.

34. Williams DR, Yan Y, Jackson JS, Anderson NB. Racial differences in physical and mental health: socio-economic status, stress and discrimination. J Health Psychol. 1997;2(3):335-351. doi:10.1177/1359 10539700200305 
35. Ware JE Jr., Sherbourne CD, The MOS. 36-item short-form health survey (SF-36). I. Conceptual framework and item selection. Med Care. 1992;30(6):473-483. doi:10.1097/00005650-199206000-00002

36. Ruscheweyh R, Marziniak M, Stumpenhorst F, Reinholz J, Knecht S. Pain sensitivity can be assessed by self-rating: development and validation of the pain sensitivity questionnaire. Pain. 2009;146 (1):65-74. doi:10.1016/j.pain.2009.06.020

37. Sullivan MJL, Bishop SR, Pivik J. The pain catastrophizing scale: development and validation. Psychol Assess. 1995;7(4):524-532. doi:10.1037/1040-3590.7.4.524

38. Waugh OC, Byrne DG, Nicholas MK. Internalized stigma in people living with chronic pain. $J$ Pain. 2014;15(5):550e551-510. doi:10.1016/j.jpain.2014.02.001

39. Tan G, Jensen MP, Thornby JI, Shanti BF. Validation of the brief pain inventory for chronic nonmalignant pain. J Pain. 2004;5(2):133-137. doi:10.1016/j.jpain.2003.12.005

40. Zelman DC, Gore M, Dukes E, Tai KS, Brandenburg N. Validation of a modified version of the brief pain inventory for painful diabetic peripheral neuropathy. J Pain Symptom Manag. 2005;29(4):401-410. doi:10.1016/j.jpainsymman.2004.06.018

41. Rosen SF, Ham B, Drouin S, et al. T-Cell mediation of pregnancy analgesia affecting chronic pain in mice. J Neurosci. 2017;37 (41):9819-9827. doi:10.1523/JNEUROSCI.2053-17.2017

42. Mercader M, Bodner BK, Moser MT, et al. T cell infiltration of the prostate induced by androgen withdrawal in patients with prostate cancer. Proc Natl Acad Sci U S A. 2001;98(25):14565-14570. doi:10.1073/pnas.251140998

43. Martin LJ, Acland EL, Cho C, et al. Male-specific conditioned pain hypersensitivity in mice and humans. Curr Biol. 2019;29(2):192-201. doi:10.1016/j.cub.2018.11.030

44. Martin LJ, Hathaway G, Isbester K, et al. Reducing social stress elicits emotional contagion of pain in mouse and human strangers. Curr Biol. 2015;25(3):326-332. doi:10.1016/j.cub.2014.11.028

45. Igler EC, Defenderfer EK, Lang AC, Bauer K, Uihlein J, Davies WH. Gender differences in the experience of pain dismissal in adolescence. J Child Health Care. 2017;21(4):381-391. doi:10.1177/ 1367493517727132

46. Miller MM, Allison A, Trost Z, et al. Differential effect of patient weight on pain-related judgements about male and female chronic low back pain patients. J Pain. 2017.

47. Robinson ME, Wise EA, Gagnon C, Fillingim RB, Price DD. Influences of gender role and anxiety on sex differences in temporal summation of pain. J Pain. 2004;5(2):77-82. doi:10.1016/j.jpain.2003.11.004

48. Woolf CJ. Central sensitization: implications for the diagnosis and treatment of pain. Pain 2011;152(3, Supplement):S2-S15. doi:10.1016/j.pain.2010.09.030

49. Staud R, Robinson ME, Price DD. Temporal summation of second pain and its maintenance are useful for characterizing widespread central sensitization of fibromyalgia patients. $J$ Pain. 2007;8 (11):893-901. doi:10.1016/j.jpain.2007.06.006
50. Bartley EJ, King CD, Sibille KT, et al. Enhanced pain sensitivity among individuals with symptomatic knee osteoarthritis: potential sex differences in central sensitization. Arthritis Care Res (Hoboken). 2016;68(4):472-480. doi:10.1002/acr.22712

51. Jensen MT, Petersen KL. Gender differences in pain and secondary hyperalgesia after heat/capsaicin sensitization in healthy volunteers. $J$ Pain. 2006;7(3):211-217. doi:10.1016/j.jpain.2005.10.013

52. Goodin BR, Bulls HW, Herbert MS, et al. Temporal summation of pain as a prospective predictor of clinical pain severity in adults aged 45 years and older with knee osteoarthritis: ethnic differences. Psychosom Med. 2014;76(4):302-310. doi:10.1097/PSY.0000000000000058

53. Sarlani E, Grace EG, Reynolds MA, Greenspan JD. Sex differences in temporal summation of pain and aftersensations following repetitive noxious mechanical stimulation. Pain. 2004;109(1):115-123. doi:10.1016/j.pain.2004.01.019

54. Rametti G, Junque C, Zubiaurre-Elorza L, et al. Cortical thickness in untreated transsexuals. Cereb Cortex. 2012;23(12):2855-2862. doi:10.1093/cercor/bhs267

55. Guillamon A, Junque C, Gomez-Gil E. A review of the status of brain structure research in transsexualism. Arch Sex Behav. 2016;45 (7):1615-1648. doi:10.1007/s10508-016-0768-5

56. Savic I, Arver S. Sex dimorphism of the brain in male-to-female transsexuals. Cereb Cortex. 2011;21(11):2525-2533. doi:10.1093/ cercor/bhr032

57. Pool CW, Swaab DF, Hofman MA, Kruijver FPM, Gooren LJG, Zhou J-N. Male-to-female transsexuals have female neuron numbers in a limbic nucleus. J Clin Endocrinol Metab. 2000;85(5):2034 2041. doi:10.1210/jcem.85.5.6564

58. Garcia-Falgueras A, Swaab DF. A sex difference in the hypothalamic uncinate nucleus: relationship to gender identity. Brain. 2008;131(Pt 12):3132-3146. doi:10.1093/brain/awn276

59. Hahn A, Kranz GS, Küblböck M, et al. Structural connectivity networks of transgender people. Cereb Cortex. 2014;25(10):3527-3534. doi:10.1093/cercor/bhu194

60. Bao A-M, Swaab DF. Sexual differentiation of the human brain: relation to gender identity, sexual orientation and neuropsychiatric disorders. Front Neuroendocrinol. 2011;32(2):214-226. doi:10.1016/ j.yfrne.2011.02.007

61. Eagly AH. The his and hers of prosocial behavior: an examination of the social psychology of gender. Am Psychol. 2009;64(8):644-658. doi:10.1037/0003-066X.64.8.644

62. Martin CL, Ruble D. Children's search for gender cues: cognitive perspectives on gender development. Curr Dir Psychol Sci. 2004;13 (2):67-70. doi:10.1111/j.0963-7214.2004.00276.x

63. Nobili A, Glazebrook C, Arcelus J. Quality of life of treatment-seeking transgender adults: a systematic review and meta-analysis. Rev Endocr Metab Disord. 2018;19(3):199-220. doi:10.1007/s11154-018-9459-y
Journal of Pain Research

\section{Publish your work in this journal}

The Journal of Pain Research is an international, peer reviewed, open access, online journal that welcomes laboratory and clinical findings in the fields of pain research and the prevention and management of pain Original research, reviews, symposium reports, hypothesis formation and commentaries are all considered for publication. The manuscript

Submit your manuscript here: https://www.dovepress.com/journal-of-pain-research-journa management system is completely online and includes a very quick and fair peer-review system, which is all easy to use. Visit http:// www.dovepress.com/testimonials.php to read real quotes from published authors. 